\title{
Supplementary Information on:
}

\section{Mass Spectrometry of Refractory Black Carbon Particles From Six Different Sources: Carbon Clusters and Oxygenated Ions}

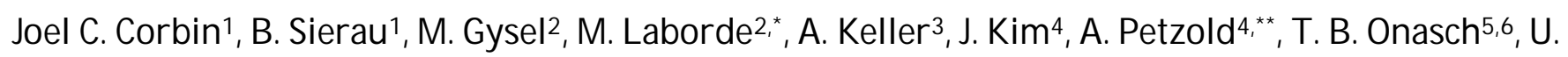
Lohmann ${ }^{1}$ and A. A. Mensah ${ }^{1}$

1ETH Zurich, Institute for Atmospheric and Climate Science, Switzerland;

${ }^{2}$ Laboratory of Atmospheric Chemistry, Paul Scherrer Institute, 5232 Villigen PSI, Switzerland;

3Institute for Aerosol Sensor Technology, FHNW, Switzerland;

${ }^{4}$ Deutsches Zentrum für Luft- und Raumfahrt, Institut für Physik der Atmosphäre, 82234 Oberpfaffenhofen, Germany.

${ }^{5}$ Aerodyne Research Inc., Billerica, Massachusetts, USA.

${ }^{6}$ Boston College, Chestnut Hill, Massachusetts, USA. 


\section{SP-AMS Nomenclature}

This section illustrates the distinctions between SP-AMS- and AMS-measured species in terms of a twodimensional space: (i) vapourization temperature and (ii) light-absorption efficiency at $1064 \mathrm{~nm}$.

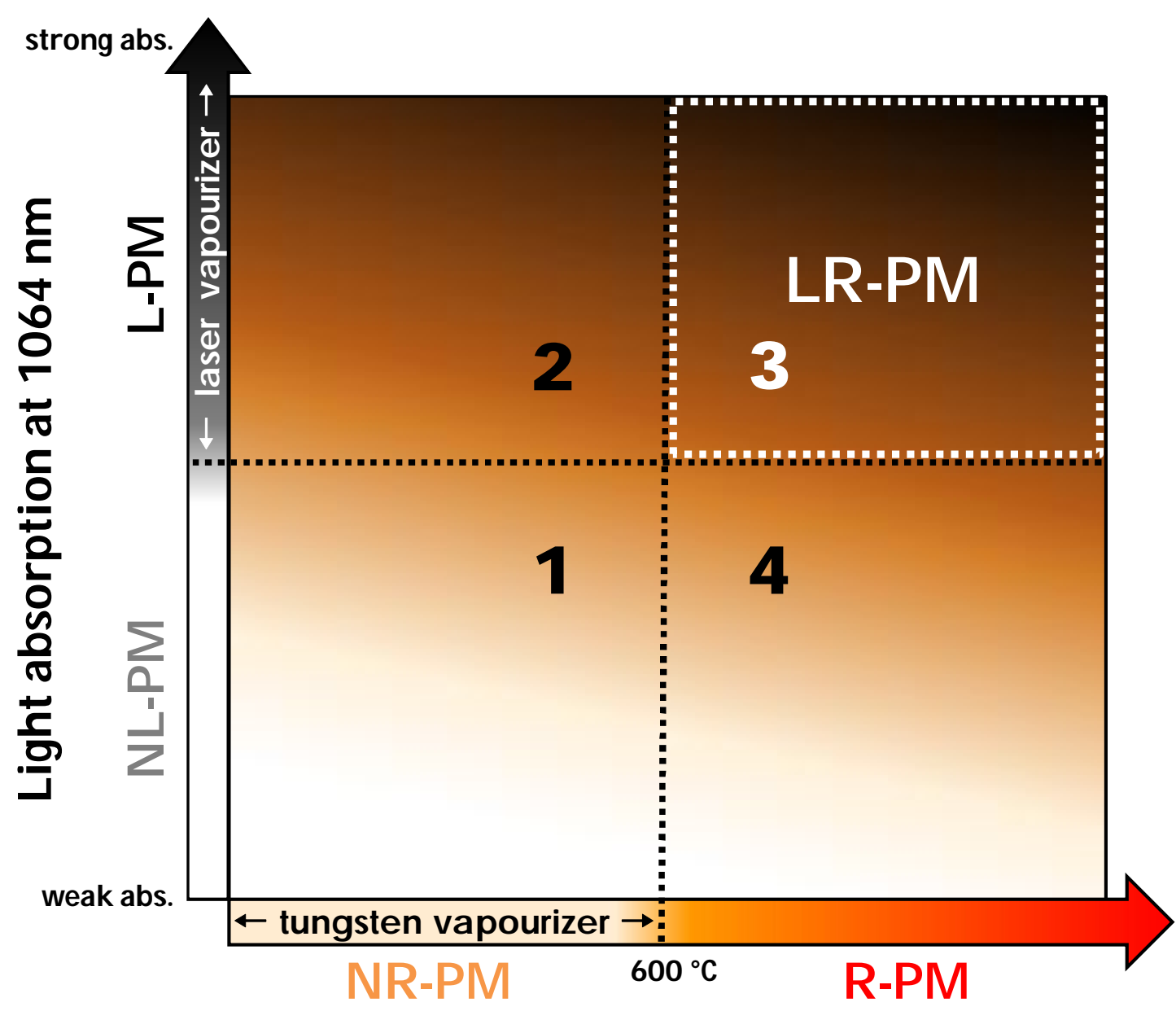

Vapourization temperature

Figure S1. Illustration of the measurement domains of the AMS and SP-AMS vapourizers. The AMS vapourizes species which vapourize rapidly at $600{ }^{\circ} \mathrm{C}$ ("NR-PM”). The SP-AMS vapourizes species which absorb sufficient $1064 \mathrm{~nm}$ laser light ("L-PM"). The SP-AMS therefore provides the new measurement domain of refractory, $1064 \mathrm{~nm}$ light-absorbing PM ("LR-PM", smaller shaded region). The numbered regions are discussed in the text.

Figure S1 illustrates the distinction between PM species detectable by AMS ("NR-PM") and PM species detectable by SP-AMS but not AMS ( "LR-PM"), as described in the main paper (Section 1). The horizontal axis, vapourization temperature, is the property upon which vapourization by the tungsten vapourizer of the AMS depends. The vertical axis, light-absorption at $1064 \mathrm{~nm}$, is the property upon which vapourization by the laser vapourizer of the SP-AMS depends. 
The AMS detects PM species which flash-vapourize upon impaction onto a $600{ }^{\circ} \mathrm{C}$ porous-tungsten vapourizer. Therefore, the AMS detects PM species in Regions 1 and 2, together termed "NR-PM" (nonrefractory particulate matter). PM species found in Region 1 include organic matter (OM), sulphates, nitrates, and ammonium. We do not know of any PM species found in Region 2.

The SP-AMS detects PM species which absorb sufficient light at $1064 \mathrm{~nm}$ to be vapourized by radiative heating. Therefore, the SP-AMS detects PM species in Regions 2 and 3. Region 3 is of special interest as it includes refractory black carbon particles ( $\mathrm{rBC}$ ), metallic particles, and absorbing minerals such as hematite. These refractory, 1064 nm light-absorbing particles are termed "LR-PM." The present study focusses on $\mathrm{rBC}$, which is a carbonaceous example of LR-PM.

Those PM species in Region 4 are not detected by AMS nor SP-AMS. Region 4 may include some types of organic matter, inorganic salts, or minerals such as kaolinite. Region 4 species may be detected by the SPAMS if they are internally-mixed with LR-PM of a higher vapourization temperature.

\section{Selected Mass Spectra}

This supplementary section includes the raw high-resolution mass spectra for two samples, in support of the discussion in the paper. 


\subsection{CBW}

Number of carbons in singly-charged cluster
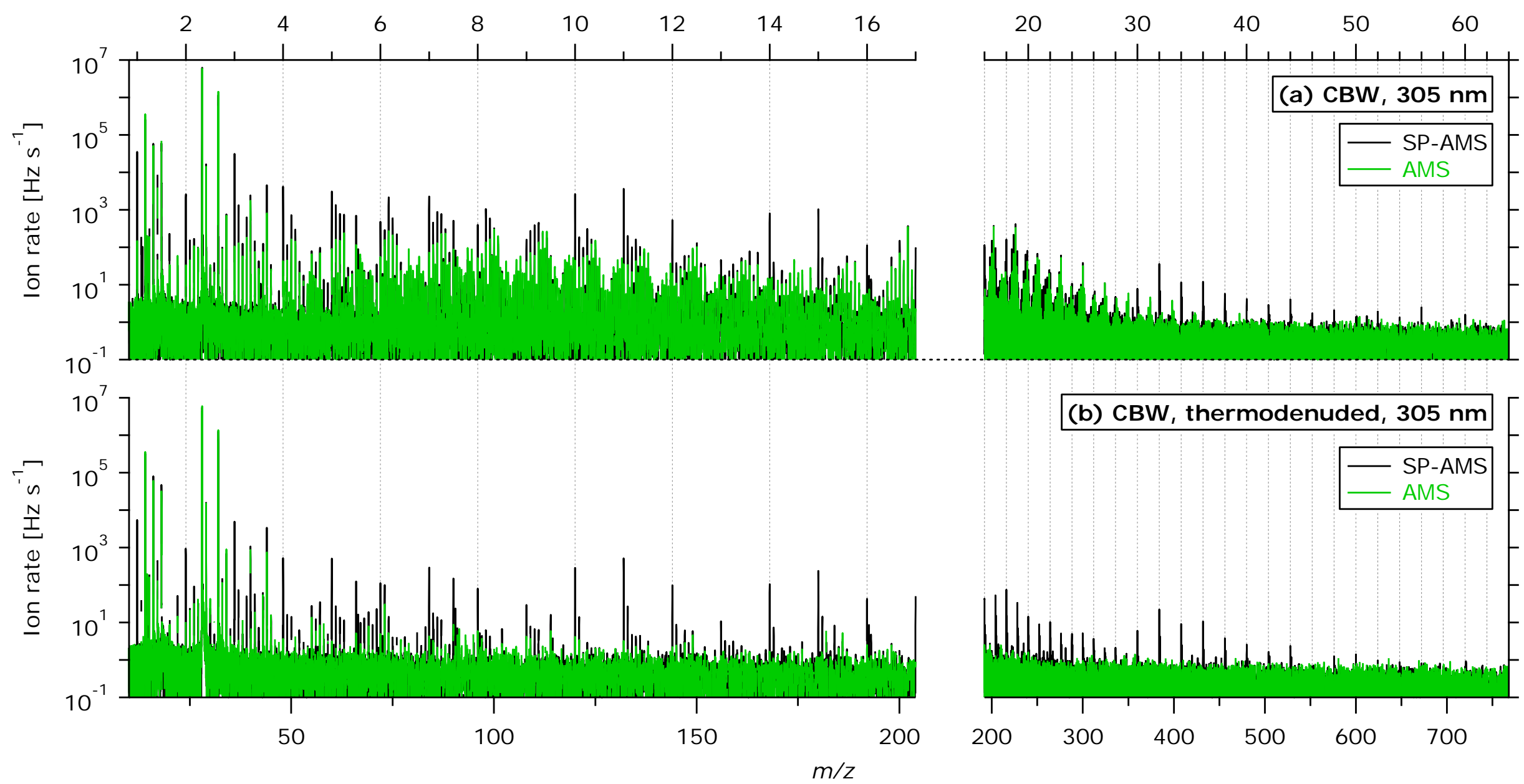

Figure S2. Mass spectra of (a) nascent CBW and (b) CBW thermodenuded at $250{ }^{\circ} \mathrm{C}$. The left and right abscissas have different scales for clarity. All gridlines are spaced by $24 \mathrm{u}$ (two carbon atoms). Background levels are about $0.5 \mathrm{~Hz} \mathrm{~s}^{-1} \mathrm{up}$ to $\mathrm{m} / \mathrm{z} 200$ and decreasing at higher $\mathrm{m} / \mathrm{z}$ in (a). The background is slightly

lower in (b) since the reduced signals allowed the detector to relax between ion arrival events. After thermodenuding (b), the green AMS signals are considerably reduced, whereas $\mathrm{C}_{x}^{n+}$ signals (e.g. the fullerenes at $m / z>384$ ) remain. The labelled diameter in (b) is the mobility size after thermodenuding. 


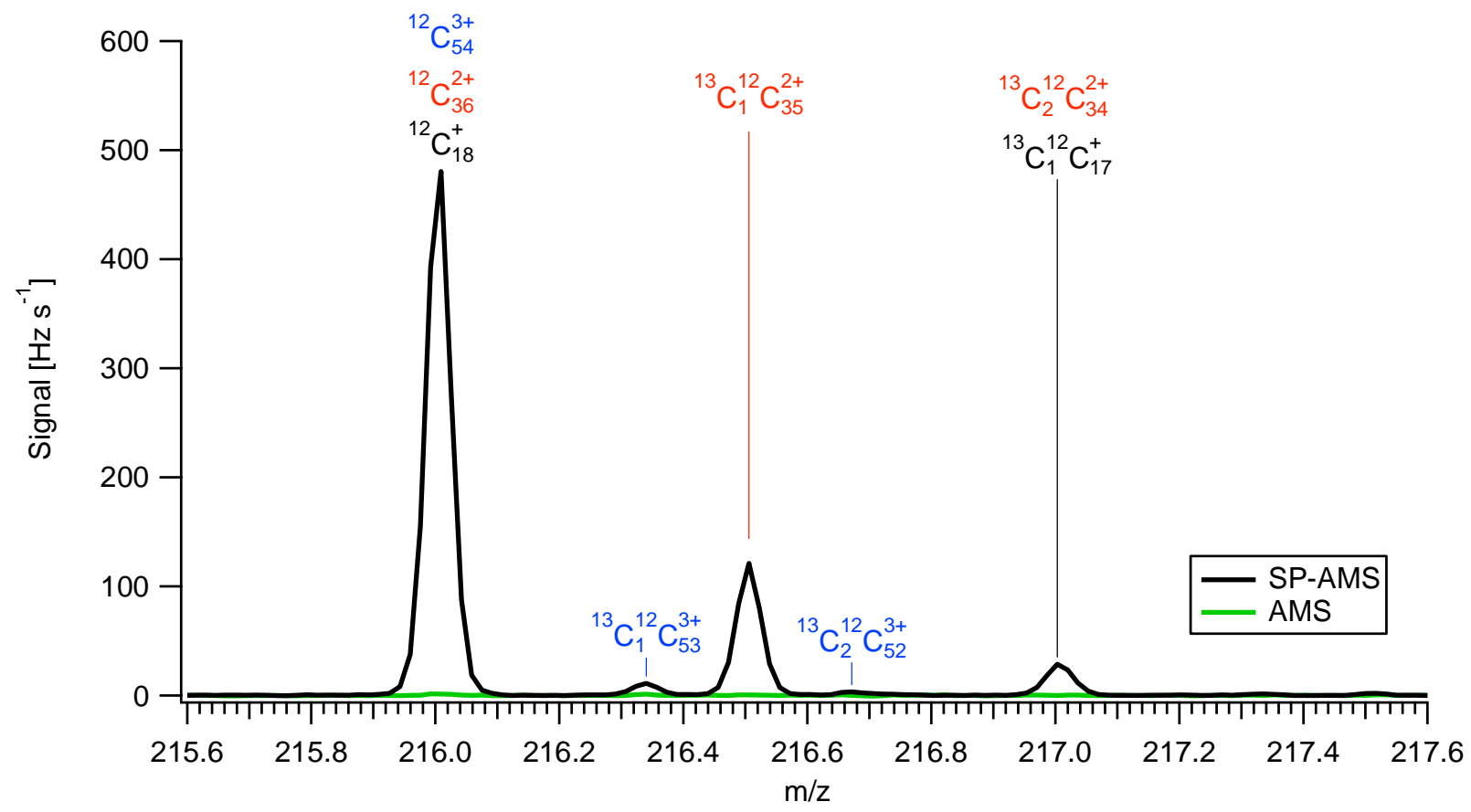

$3 \quad$ Figure S3. The three overlapping $C_{x}^{n+}$ ions at $m / z 216.00\left(C_{18}^{+}, C_{36}^{2+}\right.$, and $\left.C_{54}^{3+}\right)$, indicated by the isotopic

4 peaks as labelled. No $\mathbf{C}_{72}^{4+}$ isotope peak was observed ( $\left.\boldsymbol{m} / \mathbf{z} 216.25\right)$. Gaussian fits to the peaks at $\boldsymbol{m} / \mathbf{z} 216.33$

5 and 216.66 match the predicted $\mathbf{C}_{\mathbf{5 4}}$ isotopic ratio within uncertainty, whereas this ratio for $\boldsymbol{m} / \mathbf{z} 216.00$ to

$6 \quad 216.50$ is $24.7 \pm 0.3 \%$, lower than the predicted $39.4 \%$ for $\mathbf{C}_{\mathbf{3 6}}$. This indicates the presence of significant $\mathbf{C}_{\mathbf{1 8}}$ at

$7 \mathbf{m} / \mathbf{z} 216.00$ (and 217.00). Based on the isotopic peak areas at 216.33 and 216.50, the major peak at $\boldsymbol{m} / \mathbf{z}$

$8 \quad 216.00$ is $33.1 \pm 0.6 \% \mathbf{C}_{\mathbf{1 8}}, 62.8 \pm 0.8 \% \mathbf{C}_{\mathbf{3 6}}$ and $4.1 \pm 0.6 \% \mathbf{C}_{\mathbf{5 4}}$ using a relative abundance of carbon-13 of

$9 \quad \mathbf{1 . 0 8 1 5 7 \%}$ (de Laeter et al., 2003). This abundance was confirmed at ${ }^{\mathbf{1 3}} \mathbf{C}_{\mathbf{1}}^{+}$. 


\section{SP-AMS C ${ }_{x}^{+}$Mass Spectra up to $m / z 200$}

This section contains graphs for each rBC sample, corresponding to the data plotted in Figure 4 of the paper. The $\mathrm{C}_{x}^{+}$ions were fitted using PIKA 1.10H according to the software fitting routines. Since multiply-charged $\mathrm{C}_{x}^{n+}$ were observed for selected $m / z(72,192, \ldots)$, isotopic constraints were removed during $\mathrm{C}_{x}^{+}$fitting. " $\mathrm{C}_{x}^{+ \text {" }}$ is defined as $\mathbf{C}_{1 \leq x \leq 16}^{+}$and the corresponding isotope ions, as explained in Section 3.1 of the paper.

\subsection{FS}

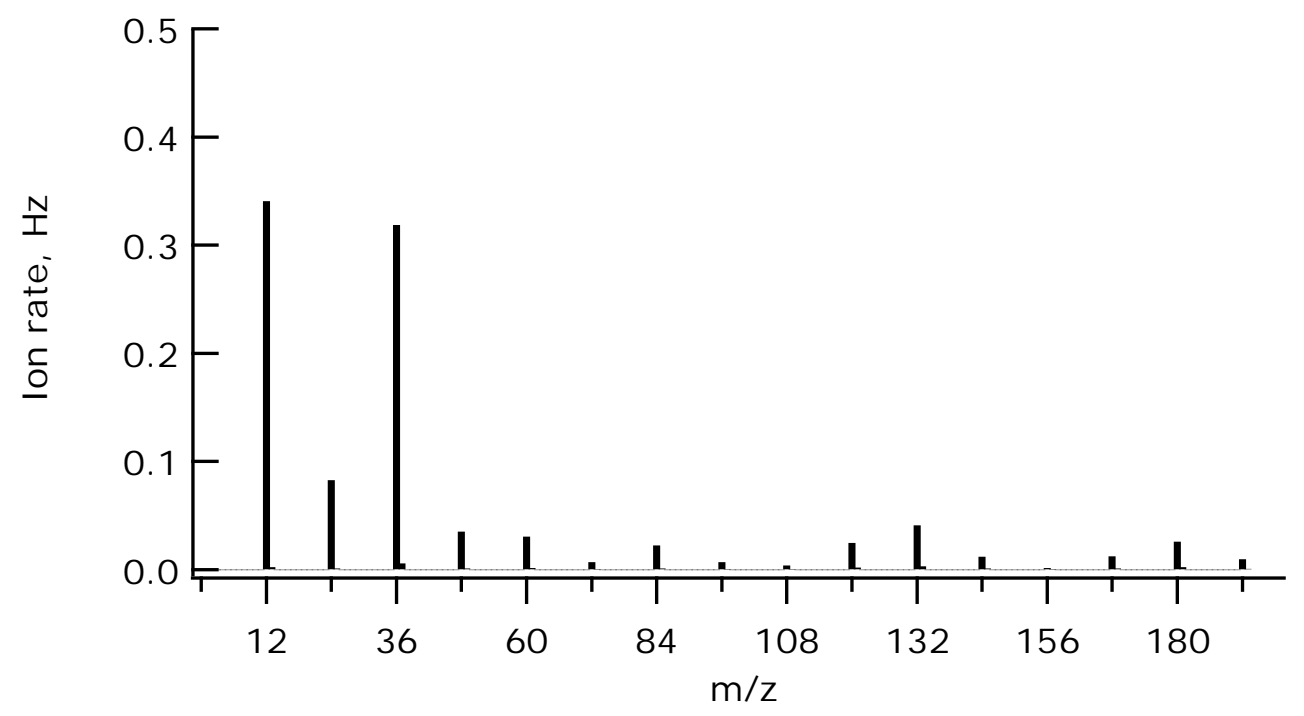

Figure S4. $\mathrm{C}_{x}^{+}$mass spectrum for Fullerene Soot (FS), showing nominally singly-charged ions $\mathrm{C}_{1 \leq x \leq 16}^{+}$. 


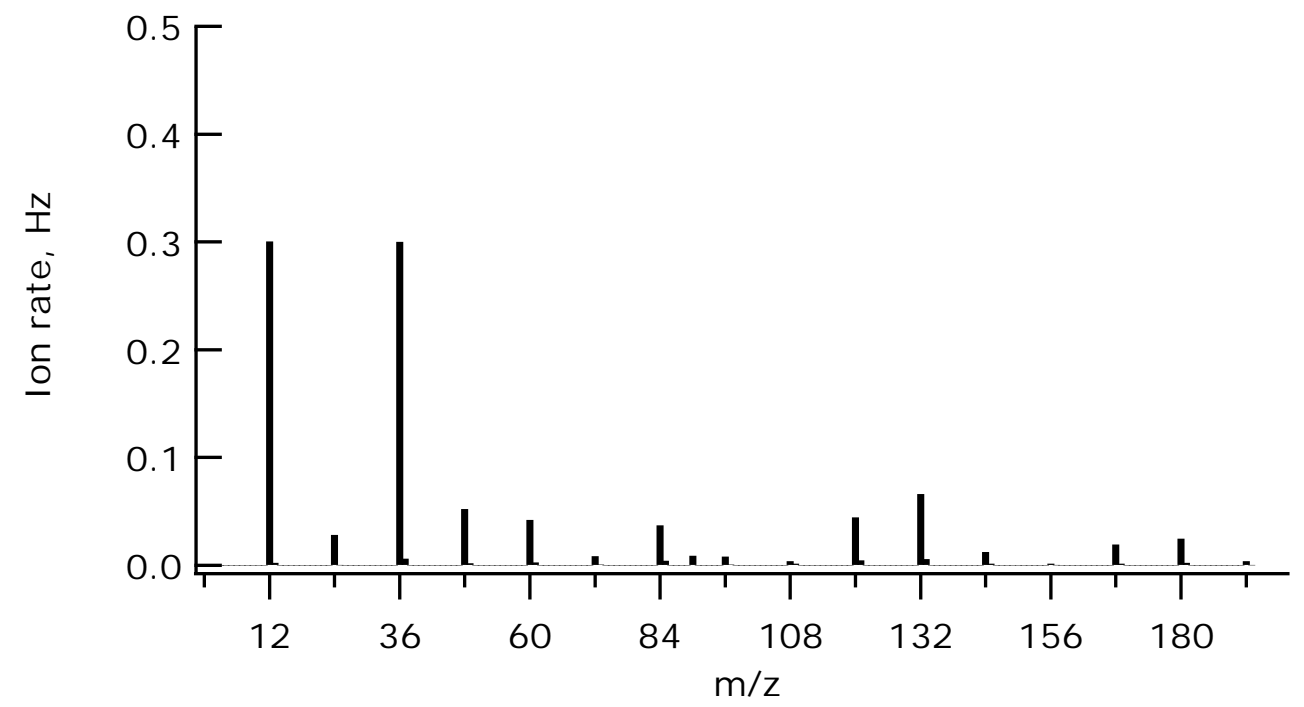

Figure S5. $\mathrm{C}_{x}^{+}$mass spectrum for CAST Brown, showing nominally singly-charged ions $\mathrm{C}_{1 \leq x \leq 16}^{+}$.

\subsection{GFG}

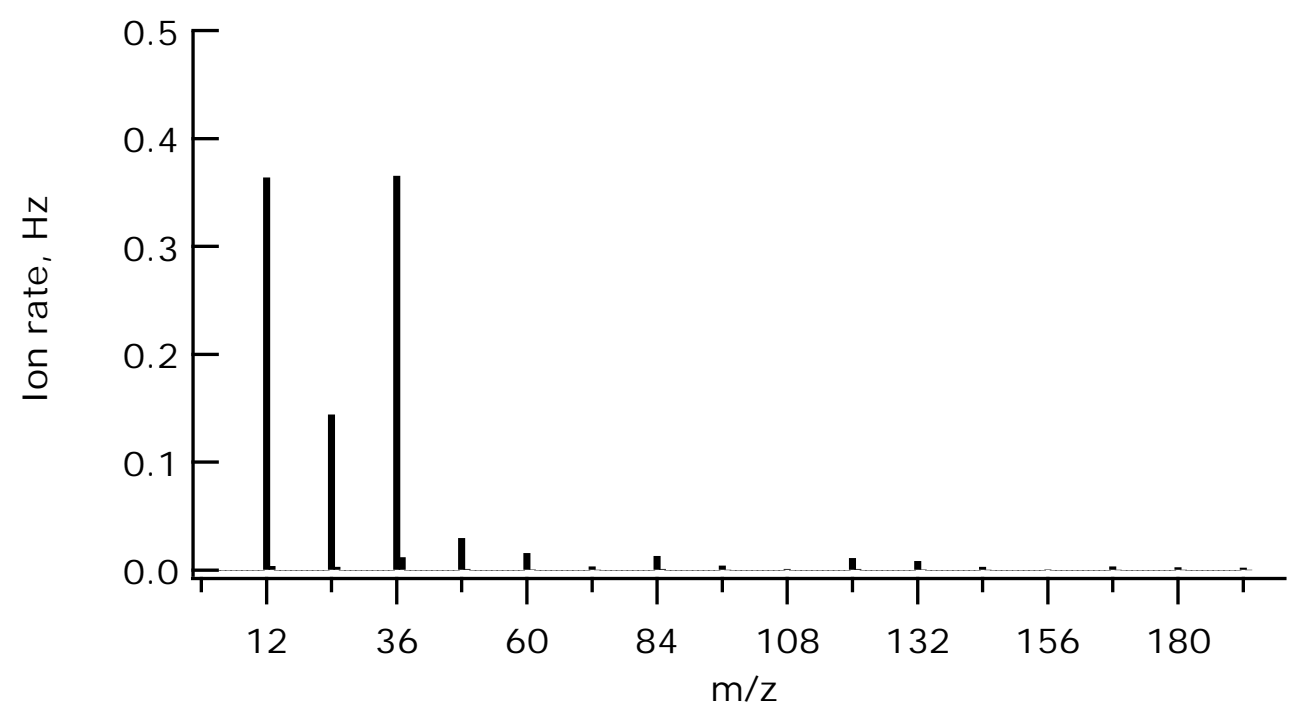

27

Figure S6. $\mathrm{C}_{x}^{+}$mass spectrum for GFG, showing nominally singly-charged ions $\mathrm{C}_{1 \leq x \leq 16}^{+}$. 


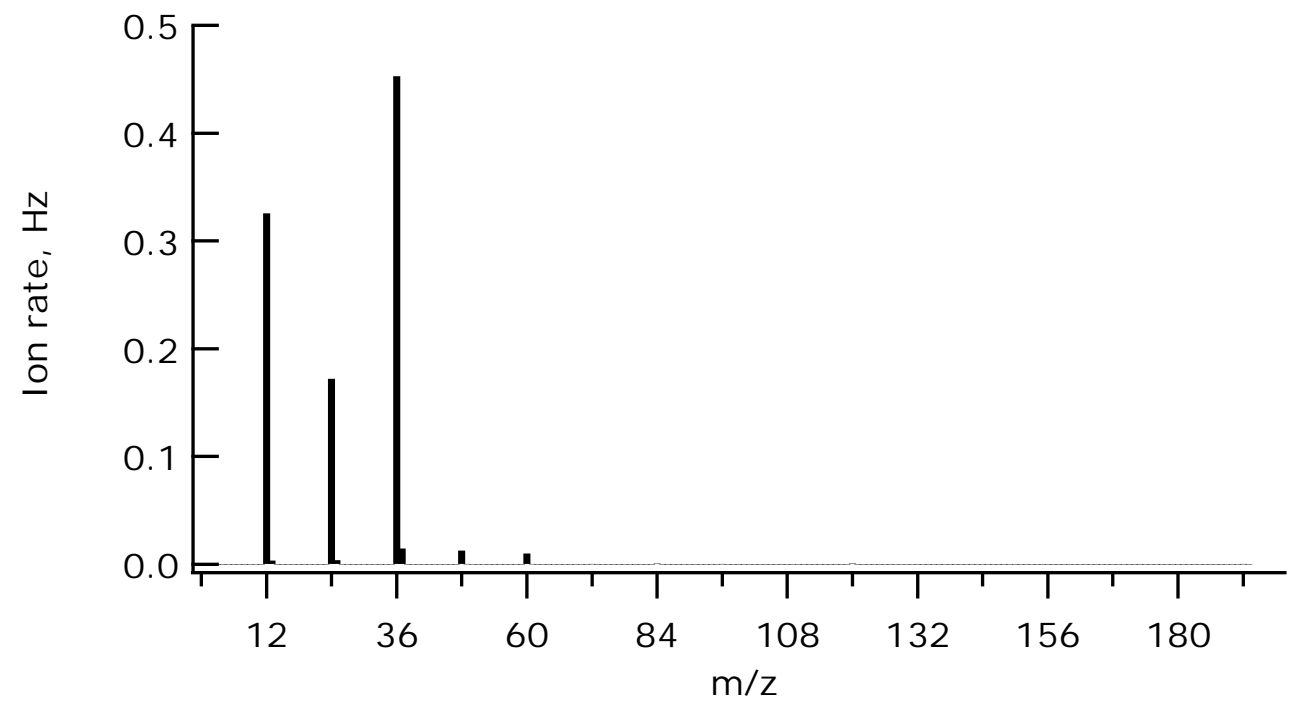

Figure S7. $C_{x}^{+}$mass spectrum for aircraft-turbine particles, showing nominally singly-charged ions $\mathrm{C}_{1 \leq x \leq 16}^{+}$.

\section{$3.5 \mathrm{RB}$}

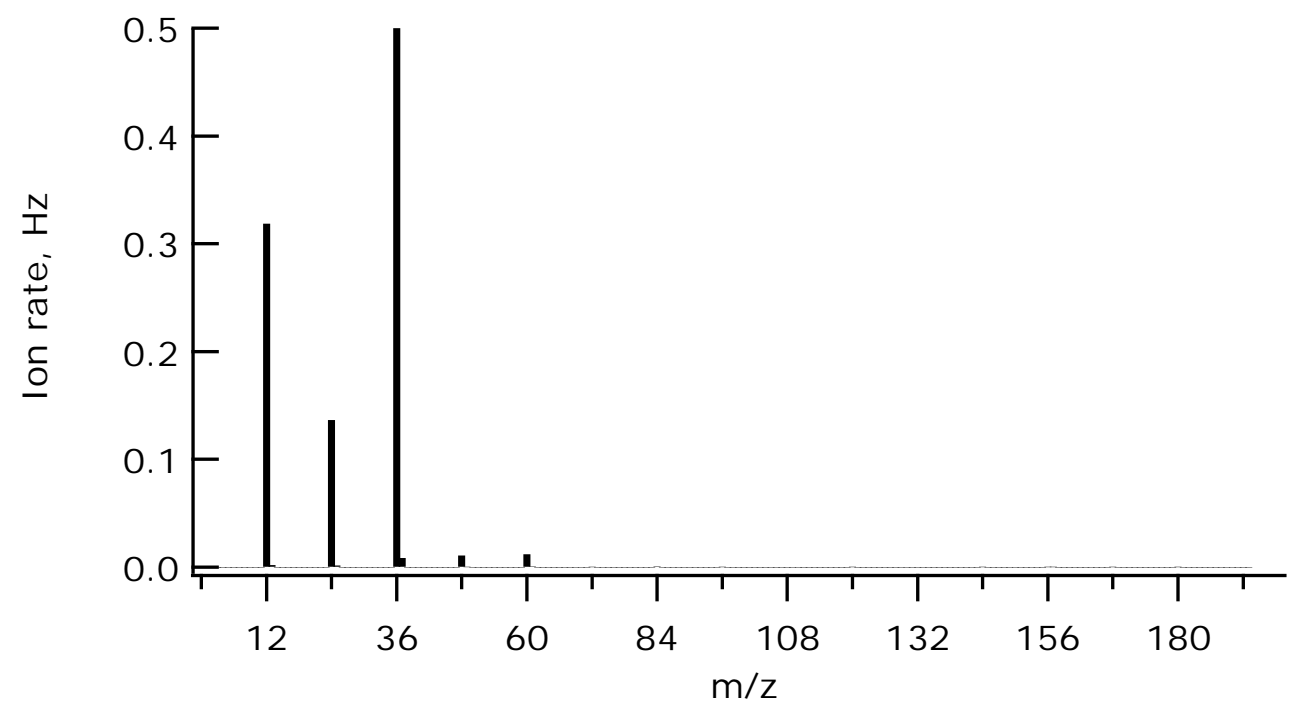

Figure S8. $C_{x}^{+}$mass spectrum for Regal Black, showing nominally singly-charged ions $C_{1 \leq x \leq 16}^{+}$. 


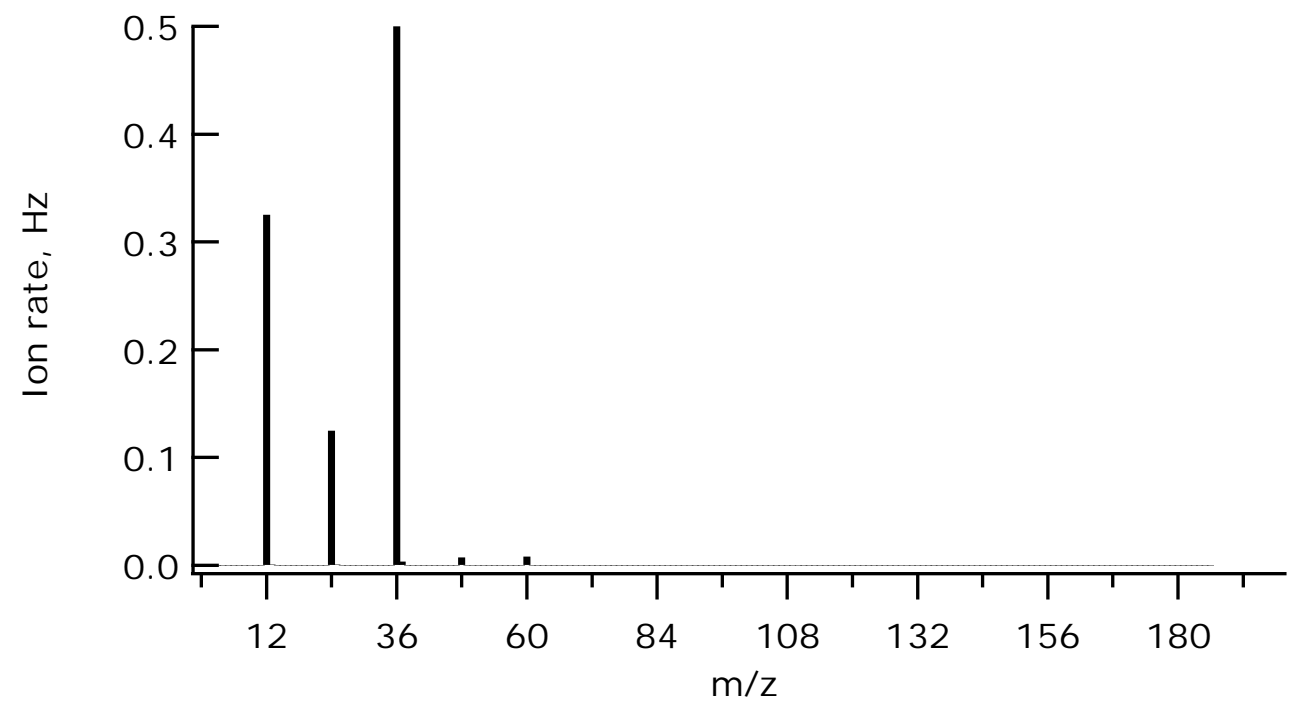

Figure S9. $\mathrm{C}_{x}^{+}$mass spectrum for CAST Black, showing nominally singly-charged ions $\mathrm{C}_{1 \leq x \leq 16}^{+}$. 


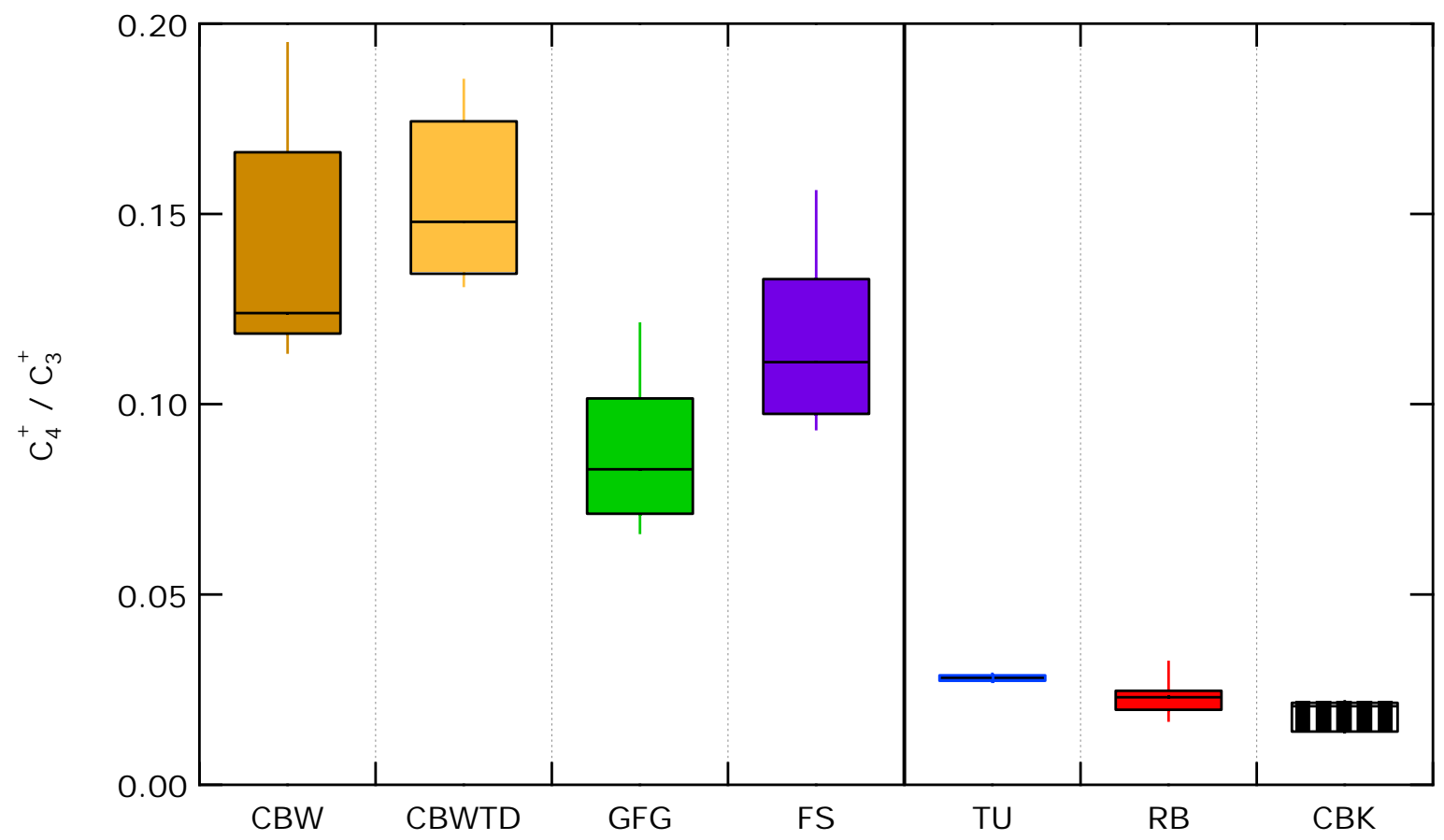

Figure S10. SP-AMS C ${ }_{4}^{+} / \mathrm{C}_{3}^{+}$ratios for Fullerene-enriched Soot (FS), CAST "Brown" (CBW), CAST "Black" (CBK), spark-generated particles (GFG), aircraft-turbine particles (TU), and Regal Black (RB). A similar distinction is seen as for $\mathrm{C}_{1}^{+} / \mathrm{C}_{3}^{+}$(Figure 4, main paper), in that the samples are divided according to their $\mathrm{C}_{x}^{+}$mass spectra. Some other ratios for $\mathrm{C}_{x<6}^{+}$also showed this trend, but all used $\mathrm{C}_{x<3}^{+}$ and therefore would likely incur higher organic interferences than $\mathrm{C}_{4}^{+} / \mathrm{C}_{3}^{+}$. 


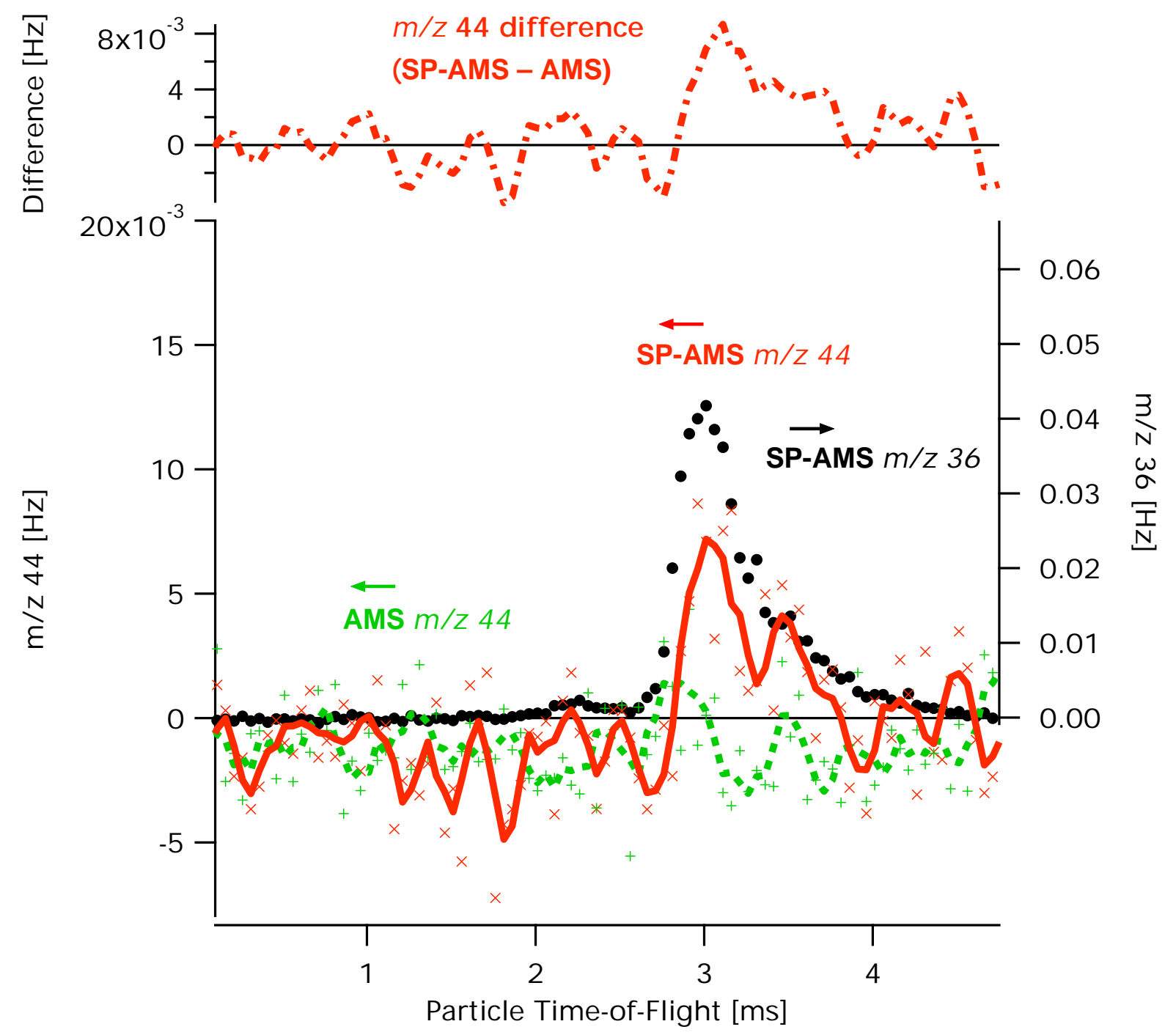

Figure S11. Signal at $\mathrm{m} / \mathrm{z} 44\left(\mathrm{CO}_{2}^{+}\right)$as a function of time for polydisperse Regal Black particles. SP-AMS raw data at $m / z 44$ are shown by $\times$ symbols, AMS data by + symbols. The $\bullet$ symbols show SP-AMS raw data at $m / z$ 36. All $m / z 44$ data are plotted on the left axis whereas $m / z 36$ is plotted on the right. The low er curves (solid, SP-AMS; dashed, AMS) show the same data smoothed (4th-order 11-point Savitsky-Golay filter) and the upper curve is the difference of the two lower curves. The mode coincidences with that of $m / z 28$ in Figure 6 of the main text. 


\section{Additional Instrumentation}

\subsubsection{Single Particle Soot Photometer (SP2)}

The Single Particle Soot Photometer (SP2, Droplet Measurement Technologies, Colorado USA) employs a $1064 \mathrm{~nm}$ continuous-wave Nd:YAG laser similar to that of the SP-AMS, but at a lower laser fluence (Onasch et al., 2012;Schwarz et al., 2010). Whereas the SP-AMS analyzes vapourized $\mathrm{rBC}$, the SP2 measures the rBC incandescence resulting from laser heating. This incandescence can be calibrated to give the rBC mass per particle (Schwarz et al., 2006;Laborde et al., 2012). Complete details of SP2 operation and calibration during this study are provided by Gysel et al. (2012). The SP2 measured particles behind the same DMA as the SP-AMS.

\subsubsection{Aerosol Particle Mass Analyzer (APM)}

An Aerosol Particle Mass analyzer (APM, Kanomax APM-II, model 3601; (Ehara et al., 1996)) was used to determine the absolute mass of particles exiting the DMA. The APM introduces particles into the annular region between two rotating cylinders, across which a voltage is applied. The resulting centrifugal and electrostatic forces are then balanced to select particles of a given mass-to-charge ratio, independent of morphology. Particles of greater or lesser mass-per-charge are impacted on the cylinder walls.

The mass of singly-charged particles selected by the DMA was determined by scanning the APM voltage at fixed rotation speed. During a scan, the concentration of transmitted particles was monitored using a Condensation Particle Counter (CPC, TSI 3022, TSI Inc. USA). The single-particle mass was then determined from the mass setpoint at which the maximum number of particles was observed, as described in detail by Gysel et al. (2012).

\section{Non-Refractory Particulate Matter}

This section gives a general overview of the non-refractory particulate matter (NR-PM) of three of the six samples as a background to the $C_{x}^{n+}$ spectrum discussion in the paper. The 
remaining three samples (FS, $\mathrm{RB}$ and $\mathrm{CBK}$ ) are not discussed in detail because they contained $<10 \%$ NR-PM, based on a comparison of the AMS organic mass and the total mass estimated from the CPC number concentration and APM single-particle mass, using an SP2-based doubly-charged particle correction. A discussion of the NR-PM content of $\mathrm{CBW}, \mathrm{GFG}$ and TUin the context of the main paper is given below .

\subsection{CBW}

For CBW, significant OM was observed by the AMS, with a mass spectrum indicative of polyaromatic hydrocarbons (PAHs) (Figure S2). This OM is consistent with thermal EC/ OC analysis of a similar CAST burner (Schnaiter et al., 2006), and AMS measurements of soot from a different diffusion flame (Slowik et al., 2004). Compared to Slowik et al. (2004), the mass spectrum of our sample (Figure S2A) indicates a relatively greater contribution of hydrocarbon ions at $m / z<100$, possibly due to a relatively high contribution from aliphatic compounds. In order to investigate the influence of these compounds on the SPAMS mass spectrum, additional experiments were performed where CBW was thermodenuded at $250{ }^{\circ} \mathrm{C}$ prior to DMA selection. The resulting AMS mass spectrum (Figure S2B) showed almost negligible signal, while the SP-AMS spectrum retained the characteristic ions discussed in the paper.

\subsection{GFG}

Two sources of OM were possible for GFG particles, (i) contamination from the polyamide chamber of the generator (Roth et al., 2004) and contamination by OM from CBW, which was sampled immediately before GFG. CBW contamination was determined from the $\mathrm{PAH}$ fragmentation pattern at $m / z 202\left(\mathrm{C}_{16} \mathrm{H}_{10}\right)$, which was the major PAH signal. Signals from less-volatile PAH at higher $\mathrm{m} / \mathrm{z}$ were not observed. A maximum organic mass of $16 \%$ relative to the total APM-CPC mass was observed for the first GFG experiment after CBW (305 nm), which fell to $<8 \%$ for the remaining experiments. No difference was observed in the $\mathrm{C}_{x}^{n+}$ spectrum over time for GFG, indicating that these contaminations did not influence the signals discussed in this paper. 
It is worth noting that the SP2 was unable to bring GFG particles to incandescence, due to exceptionally high conductive heat loss to the gas phase (Gysel et al., 2012). This is discussed by Gysel et al. (2012) in terms of the fractal shape, very low effective density, and very small primary-particle diameter $(5-10 \mathrm{~nm}$ ) of these particles. This cooling effect is not expected to apply to the SP-AMS, since vapourization occurs in a near vacuum (10-5 torr, (DeCarlo et al., 2006)), however, the fractal shape of GFG particles may result in less efficient particle focussing by the AMS aerodynamic lens (Huffman et al., 2005).

\subsection{TU}

For airplane gas-turbine particles, the significantly different sampling configuration required a different approach to the SP-AMS data. Turbine conditions were determined as part of a larger initiative (Crayford, 2012), and monodisperse samples were not feasible. The polydisperse particles were very small (mode diameter $\sim 25 \mathrm{~nm}$ ), irregularly-shaped, and contained varying amounts of OM. Such small particles are poorly focussed by the AMS aerodynamic lens, for which transmission begins to decrease dramatically below $60 \mathrm{~nm}$ for spherical particles (Zhang et al., 2004). Focussing decreases further still for irregular particles (Huffman et al., 2005), although this shape effect is weaker than the size effect. Furthermore, particle focussing is more of an issue for the SP-AMS than the AMS, due to its smaller vapourizer (SP-AMS laser full-width half-maximum: $\sim 0.50 \mathrm{~mm}$; AMS vapourizer: $3.81 \mathrm{~mm}$ diameter (Huffman et al., 2005;Onasch et al., 2012)), although the orthogonal orientation of the SP-AMS laser beam to the particle beam may slightly increase its effective area. A comparison of AMS and SP-AMS signals for TU is therefore non-trivial.

The at-times significant $\mathrm{OM}$ content of TU presents a separate problem. As organic molecules generate $\mathrm{C}_{x}^{+}$ions for $1<x<3$ even in the AMS (albeit with much lower relative yields than for $\mathrm{rBC}$ ), interference in the SP-AMS spectrum by these ions can be expected. A direct comparison of $\mathrm{C}_{1-3}^{+}$production between AMS and SP-AMS spectra is unjustified: organic fragmentation during electron-impact mass spectrometry is affected by the initial temperature of the molecule in question, as is well-known for the $600{ }^{\circ} \mathrm{C}$ AMS vapourizer 
(Alfarra, 2004). For the SP-AMS, such differences in fragmentation have not been thoroughly characterized. Furthermore, with the SP-AMS laser on, an estimated $40 \%$ of the AMS tungsten vapourizer may remain exposed to the incoming particle beam, assuming a particle beam the size of the vapourizer, a $3 \sigma$ laser beam width, and a negligible parallax effect. This allows for a possible mixture of AMS and SP-AMS vapourization temperatures to exist in the vapourized particle plume. Such a mixture would complicate the mass spectrum, especially for poorly-focussed particles as expected for the turbine sample. Because the laser beam extends horizontally beyond the edges of the AMS vapourizer, this is an upper limit to the contribution of such AMS vapourization events.

In light of these two issues (organic production of $\mathrm{C}_{1-3}^{+}$; vapourizer uncertainties for poorly-focussed particles), the current work only includes data where the $\mathrm{AMS} \mathrm{C}_{1-3}^{+}$signal is minimal compared to the SP-AMS C ${ }_{1-3}^{+}$signal. Data from two sampling lines were available, one diluted by a factor of 10 and one undiluted. However, the above criterion resulted in the selection of engine emissions at maximum mass loading ( $2650 \mathrm{rpm}$ ) on the undiluted sampling line, where $\mathrm{AMS} \mathrm{C}_{1}^{+}$and $\mathrm{C}_{3}^{+}$were $5 \%$ and $1 \%$ of the SP-AMS signals, respectively. It was initially expected that the diluted sampling line would have had reduced particulate organic loading and therefore less $\mathrm{C}_{1-3}^{+}$interference. However, this was not the case. Upon 10x dilution, the observed AMS signals at $\mathrm{C}_{1}^{+}$and $\mathrm{C}_{3}^{+}$decreased by a factor of $\sim 10$, whereas the SP-AMS signals decreased by a factor of $\sim 30$. This is consistent with a change in particle focussing due to changes in particle size and/ or shape.

TU particle morphology on the diluted line was characterized by Tjong et al. (2012) during this experiment. Particles were aggregates of $\sim 10 \mathrm{~nm}$ primary spherules. Larger particles appeared fractal under TEM. At a mobility diameter of $40 \mathrm{~nm}$, particles exhibited massmobility exponents close to 2.75 , reflecting the small number of primary spherules in the aggregate. These morphological features remained similar across the measured range of turbine thrusts, indicating that particles were comparable across these setpoints. Finally, the $\mathrm{C}_{4}^{+} / \mathrm{C}_{3}^{+}$ratio was similar for all setpoints. The selected data $(2650 \mathrm{rpm}$ ) are therefore considered representative for the discussion in the main paper. 


\section{Supplement References}

Alfarra, M. R.: Insights Into Atmospheric Organic Aerosols Using An Aerosol Mass

Spectrometer, PhD Thesis, Department of Chemical Engineering, University of Manchester, 2004.

Crayford, A., M. Johnson, R. Marsh, Y. Secvenco, D. Walters, P. Williams, A. Petzold, P. Bowen, J. Wang, D. Lister: SAMPLE III: Contribution to aircraft engine PM certification requirement and standard, Second Specific Contract, Final Report, European Aviatian Safety Agency, 2012.

de Laeter, J. R., Böhlke, J. K., De Bièvre, P., Hidaka, H., Peiser, H., Rosman, K., and Taylor, P.: Atomic weights of the elements. Review 2000 (IUPACTechnical Report), Pure and Applied Chemistry, 75, 683-800, 2003.

DeCarlo, P. F., Kimmel, J. R., Trimborn, A., Northway, M. J., Jayne, J. T., Aiken, A. C., Gonin, M., Fuhrer, K., Horvath, T., and Docherty, K. S.: Field-deployable, high-resolution, time-of-flight aerosol mass spectrometer, Anal. Chem., 78, 8281-8289, 2006.

Ehara, K., Hagwood, C., and Coakley, K. J.: Novel method to classify aerosol particles according to their mass-to-charge ratio-aerosol particle mass analyser, J. Aerosol Sci., 27, 217-234, 1996.

Gysel, M., Laborde, M., Mensah, A. A., Corbin, J. C., Keller, A., Kim, J., Petzold, A., and Sierau, B.: Technical Note: The single particle soot photometer fails to reliably detect PALAS soot nanoparticles, Atmos. Meas. Tech., 5, 10.5194/ amt-5-3099-2012, 2012.

Huffman, J. A., Jayne, J. T., Drewnick, F., Aiken, A. C., Onasch, T. B., Worsnop, D. R., and Jimenez, J. L.: Design, modeling, optimization, and experimental tests of a particle beam width probe for the Aerodyne aerosol mass spectrometer, Aerosol Sci. Technol., 39, 1143$1163,2005$.

Laborde, M., Mertes, P., Zieger, P., Dommen, J., Baltensperger, U., and Gysel, M.: Sensitivity of the Single Particle Soot Photometer to different black carbon types, Atmos. Meas. Tech., 5, 10.5194/ amt-5-1031-2012, 2012.

Onasch, T. B., Trimborn, A., Fortner, E. C., Jayne, J. T., Kok, G. L., Williams, L. R., Davidovits, P., and Worsnop, D. R.: Soot Particle Aerosol Mass Spectrometer: Development, Validation, and Initial Application, Aerosol Sci. Technol., 10.1080/ 02786826.2012.663948, 2012.

Roth, C., Ferron, G., Karg, E., Lentner, B., Schumann, G., Takenaka, S., and Heyder, J.: Generation of ultrafine particles by spark discharging, Aerosol Sci. Technol., 38, 228-235, 2004.

Schnaiter, M., Gimmler, M., Llamas, I., Linke, C., Jäger, C., and Mutschke, H.: Strong spectral dependence of light absorption by organic carbon particles formed by propane combustion, Atmos. Chem. Phys., 6, 2981-2990, 10.5194/ acp-6-2981-2006, 2006. 
Schwarz, J. P., Gao, R. S., Fahey, D. W., Thomson, D. S., Watts, L. A., Wilson, J. C., Reeves, J. M., Darbeheshti, M., Baumgardner, D. G., Kok, G. L., Chung, S. H., Schulz, M., Hendricks, J., Lauer, A., Kärcher, B., Slowik, J. G., Rosenlof, K. H., Thompson, T. L., Langford, A. O., Loewenstein, M., and Aikin, K. C.: Single-particle measurements of midlatitude black carbon and lightscattering aerosols from the boundary layer to the lower stratosphere, Journal of Geophysical Research, 111, 10.1029/ 2006JD007076, 2006.

Schwarz, J. P., Spackman, J. R., Gao, R. S., Perring, A. E., Cross, E., Onasch, T. B., Ahern, A., Wrobel, W., Davidovits, P., Olfert, J., Dubey, M. K., Mazzoleni, C., and Fahey, D. W.: The Detection Efficiency of the Single Particle Soot Photometer, Aerosol Sci. Technol., 44, 612$628,10.1080 / 02786826.2010 .481298,2010$.

Slowik, J. G., Stainken, K., Davidovits, P., Williams, L., Jayne, J., Kolb, C., Worsnop, D. R., Rudich, Y., DeCarlo, P. F., and Jimenez, J. L.: Particle morphology and density characterization by combined mobility and aerodynamic diameter measurements. Part 2: Application to combustion-generated soot aerosols as a function of fuel equivalence ratio, Aerosol Sci. Technol., 38, 1206-1222, 2004.

Tjong, H., Rogak, S., Olfert, J., Johnson, T., Symonds, J., Thomson, K., and Smallwood, G.: Morphology of particles produced by aviation gas turbines, 31st Annual American Association for Aerosol Research Conference, Minneapolis, 2012.

Zhang, X., Smith, K. A., Worsnop, D. R., Jimenez, J. L., Jayne, J. T., Kolb, C. E., Morris, J., and Davidovits, P.: Numerical characterization of particle beam collimation: Part II integrated aerodynamic-lens-nozzle system, Aerosol Sci. Technol., 38, 619-638, 2004. 